\title{
A system of models for signal setting design of a signalized road network in evacuation conditions
}

\author{
F. A. Marcianò, G. Musolino \& A. Vitetta \\ Mediterranea University of Reggio Calabria, Italy
}

\begin{abstract}
This paper proposes a system of models and procedures for the signal setting design of signalized intersections in a road transport network with endogenous estimation of origin-destination path flows. The system of models and procedures is able to support signal setting design for a road transport network both in ordinary and evacuation conditions.
\end{abstract}

Keywords: signal setting, design model, evacuation conditions.

\section{Introduction}

Nowadays signal control is considered an effective strategy to increase network capacity and to mitigate congestion phenomena, as shown in several papers of scientific literature.

Current signal setting design models and procedures do not provide solutions that take into account users behaviour at path choice level in response to supply system modifications; moreover, they are not conceived for the analysis of road transport systems in evacuation conditions.

The paper presents a system of models and procedures for the signal setting design of signalized intersections in a road transport network with endogenous estimation of origin-destination path flows. The system of models and algorithms is able to support signal setting design for a road transport network both in ordinary and evacuation conditions.

The problem of signal setting design of signalized intersections in a road network is defined as an optimization problem (design model) subjected to equilibrium constraint; in other words, travel demand flows must be coherent with travel times generated by signal setting parameters. 
The design model generates and simulates potential solutions for the optimization of an objective function; the generation of the solutions is executed by a solution generator procedure, while users behaviour (path choice) is simulated through a simulation procedure.

The design model is solved by means of a heuristic genetic algorithm, while the simulation is executed by means of a dynamic within day procedure with stochastic path choice model.

The main research advancements presented in the paper concern the design model, which is able to optimize signal setting parameters taking into account the travel demand flows simulated according to a behavioural approach. The model could be considered as the the core of a Decision Support System (DSS) for the real-time management of intelligent signalized road intersection networks.

This work is part of a research project, carried out by the Laboratory for Transport Systems Analysis (LAST) of the Mediterranea University of Reggio Calabria (Italy). The general objective of the project was risk reduction in urban areas in terms of exposure through the definition and implementation of evacuation procedures [1-6]. The results concern the development of models, procedures and guidelines [7-9] for simulation in evacuation conditions of travel demand [10-12], transport supply and demand-supply interaction [13-15], path design of emergency vehicles [16-18], and pedestrian outflow from a building simulation [19-21].

\section{Literature review on signal setting design models}

This section presents a classification of signal setting design models [22], which is based on the following criteria (Table 1):

- intersections, which may be isolated or a network (including arteria);

- signal setting strategies (or signal setting design parameters), which may be based on flows or on arrival times.

Table 1: $\quad$ Signal setting design models.

\begin{tabular}{|c|c|c|c|c|}
\hline & \multirow{3}{*}{ Variables } & \multicolumn{3}{|c|}{ Signal setting strategies } \\
\hline & & \multicolumn{2}{|c|}{ flows } & \multirow{2}{*}{$\begin{array}{c}\text { Arrival } \\
\text { times }\end{array}$} \\
\hline & & Min delay & Max capacity factor & \\
\hline \multirow{2}{*}{$\begin{array}{c}\text { Isolated } \\
\text { intersections }\end{array}$} & Green timing & SIGSET & Webster, SIGCAP & MOVA \\
\hline & $\begin{array}{l}\text { Green timing and } \\
\text { scheduling }\end{array}$ & SICCO & SICCO & \\
\hline Arteria & Offset & $\begin{array}{l}\text { MAXBAND, } \\
\text { MULTIBAND }\end{array}$ & & \\
\hline $\begin{array}{c}\text { Network of } \\
\text { intersections }\end{array}$ & $\begin{array}{c}\text { Green timing and } \\
\text { offset }\end{array}$ & $\begin{array}{l}\text { TRANSYT, } \\
\text { SCOOT }\end{array}$ & $\begin{array}{l}\text { As isolated } \\
\text { intersections }\end{array}$ & $\begin{array}{l}\text { OPAC, } \\
\text { UTOPIA }\end{array}$ \\
\hline
\end{tabular}

(source: [22]) 
For isolated intersections, two design variables are defined:

- green timing, the design parameters are green time on each access and cycle time durations, assuming exogenous stages;

- green timing and scheduling, the design parameters are initial instants of green times and green time on each access and cycle time durations.

In this case, the strategy based on flows may have two objectives: minimization of total delay, with fixed or variable cycle time duration; green timing setting has been faced with convex optimization techniques in SIGSET model [23]; green timing setting and scheduling has been faced with discrete (or non linear) optimization techniques, adopted in SICCO model [24, 25]; maximization of capacity factor, given a cycle time duration; green timing setting with some restrictive assumptions on the structure of the stages has firstly studied in Webster models ([26, 27], see also [25]). Later it has been studied with linear optimization techniques in SIGCAP model [28] and further developed in several models like SIDRA [29] and OSCADY [30]; green timing setting and scheduling has been faced with discrete (or non linear) optimization techniques, as in SICCO model [24, 25].

The strategy based on arrival time with exogenous structure of stages has been studied in several methods like MOVA model.

For arteria of intersections, design variables are common cycle time duration, green time duration on each access, offset between each couple of adjacent intersections. The first two variables are the same that involve the green timing setting. Offset design is analysed in MAXBAND model and in its extension MULTIBAND [31, 32].

For a network of intersections, if the objective is the total delay minimization two approaches may be considered: coordination, which consists in offsets design, after signal setting design of each intersection with a common cycle time duration (or an its sub-multiple), to be executed through the maximization of capacity factor which is independent from offsets (to our knowledge this approach has never been implemented in any existing method); sincronization, which consists in the simultaneous design of offsets, green time and cycle time durations; the most popular models, using strategy based on flows, are TRANSYT [33] that uses euristic optimization technques and SCOOT, that may use flows monitored in real-time.

Among the strategies based on arrival times, there are: OPAC, which is a dynamic time-discrete optimization model; UTOPIA, which is a bi-level model that decomposes the problem into two interacting sub-problems: one for single intersections and one for the whole network.

The following lacks emerge from the literature review on signal setting design models:

- they do not obtain solutions that take into account users behaviour in response to signal setting parameters modifications;

- they are not conceived for the analysis of road transport systems in evacuation conditions.

According to the first point, in existing design methods travel demand flows are estimated by means of exogenous turning percentages at intersections or 
exogenous origin-destination path flows. This implies that the modification of the network has no effects on travel demand in path choice dimension, that is clearly a not realistic assumption especially in evacuation conditions.

According to the second point, the literature is still poor and, generally, the existing studies are limited to the application of signal plans empirically defined or to the adaptation of signal setting design methods originally defined for ordinary conditions, considering that turning percentages at intersections are exogenous (more details in [34]).

\section{The proposed system of models (design model)}

This section presents the framework of the proposed system of models [34].

The basic hypotesis are reported below:

- all intersections of the network have a common cycle time duration or an its sub-multiple in order to ensure the coordination among signal plans in successive cycles;

- entering flows in the network are known and concentrated in some source nodes called origin centroids (the destinations are known);

- exiting flows from the network are concentrated in some sink nodes called destination centroids;

- users choose paths according to behavioural rules.

The design model (Figure 1), based on a what-to approach, has a multi-level structure that generates and simulates potential solutions in order to optimize an objective function.

The inputs are the elements of the transport system and, in particular, the travel demand (vector of demand flows, d), the transport supply (vector of link costs on non-congested network, c, and vector of saturation flows on each access, $\mathbf{s}_{\mathbf{A T}}$ ), the initial configuration of signal setting parametres (vector, $\mathbf{y}$ ). The output is the configuration of signal setting parameters (vector of solutions at

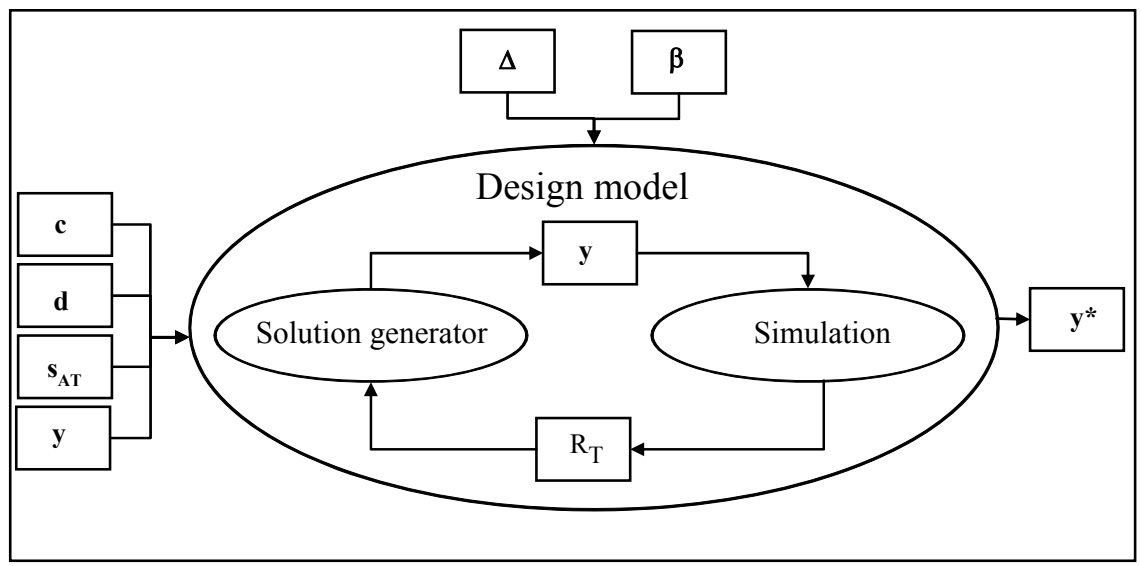

Figure 1: Components, inputs and parameters of the design model. 
equilibrium, $\mathbf{y}^{*}$ ) that optimizes the objective function. The parameters are represented by the matrix of network topology, $\Delta$, and a vector of transport models paramaters, $\beta$.

The design model is described below in terms of variables, objective function and constraints.

\subsection{Variables}

The assumption that all intesections of the network have a common cycle time duration (or an its sub-multiple) implies the design of the following variables:

- a common duration of basic cycle for all intersections;

- a sub-multiple of the basic cycle for each intersection.

As the amber time duration is not dependent from other design variables, so it is exogenous, the independent variables for each access a of an intersection, is every couple of the following variables: red time duration, green time duration, initial istant of green time, final istant of amber time.

The number of offsets to be designed (both absolute and related to each couple of intersections), depends on the duration of the basic cycle and it is equal to the number of signalized intersections less one.

\subsection{Objective function}

The objective function is defined as the global delay on the network, $\mathrm{R}_{\mathrm{T}}$, calculated as the sum of delays on all accesses of the network.

Matematically, the design problem may be formalized as follows:

Objective: $\min R_{T}(\mathbf{y}, \boldsymbol{f}(\mathbf{y}))$

with

$$
R_{T}(\mathbf{y}, \boldsymbol{f}(\mathbf{y}))=\Sigma_{\mathrm{i}=1 \ldots|I|} \Sigma_{\mathrm{j}=1 \ldots|\mathrm{Ai}|} R_{T j}(\mathbf{y}, \boldsymbol{f}(\mathbf{y}))
$$

where

$\mathrm{R}_{\mathrm{T} \mathrm{j}}$, total delay of vehicles on the access $\mathrm{j}$ belonging to the set of accesses (of numerosity $\mathrm{A}_{\mathrm{i}}$ ) that converges into the intersection $\mathrm{i}$;

$f$, link flows functions vector, which depend on the signal setting parameters at equilibrium;

$|\mathrm{I}|$, is the numerosity of the set of intersections belonging to the network.

\subsection{Constraints}

The objective function is subjected to the following constraints:

- equilibrium constraint, that is given by the vector of link flows at equilibrium, $\mathbf{f}$, that reproduces itself, according to the assignment model:

$$
f(\mathbf{y})=\Delta(\mathbf{y}) P\left(-\Delta(\mathbf{y})^{\mathrm{T}} c(f(\mathbf{y}))\right) d(g(f(\mathbf{y}))
$$

where

$\Delta$, link-path incidence functions matrix;

$\boldsymbol{P}$, probability path choice functions matrix; 
$c$, link cost functions vector;

$\boldsymbol{d}$, demand functions vector;

$\mathbf{g}$, path cost functions vector;

- technical constraints

- every set of signalized intersections that are object of cycle coordination must have the same cycle time duration, or equal to an its integer submultiples;

- for each access of an intersection the relationships between red, green and cycle times must hold;

o for each intersection the absolute offset must lie between 0 and the duration of the basic cycle;

- external constraints

o for each intersection the duration of every green phase must be greater or equal to a minimum value;

$\circ$ the duration of the basic cycle must lie between a minimum and a maximum value.

\section{Procedures}

Two procedures are defined into the design model. A solution generator procedure provides a current vector of signal setting parameters, $\mathbf{y}$; this vector is then simulated by means of a simulation procedure, which reproduces the response of the transportation system, in terms of origin-destination path flows and costs at equilibrium, to the current configuration of signal setting parameters. The response of the transport system, for each solution $\mathbf{y}$, is sintetized in a global network indicator which represents the objective function to be optimized; therefore, the solutions are compared and evaluated in terms of the values of the objective function.

The generality of the proposed design model allows the specification of different objective functions based on the global network indicator to be optimized. In this work, the specified indicator is the total delay of the vehicles on the network, $\mathrm{R}_{\mathrm{T}}$; which is relevant for signal setting design both in ordinary and evacuation conditions, because the minimization of global delay on the network implies the minimization of travel times along paths and, in particular, of the evacuation time.

\subsection{Solution generator procedure}

In the solution generator procedure new network configurations are analysed through a genetic algorithm.

Genetic algorithms are inspired by Darwin's theory of evolution. They start from a set of chromosomes (i.e. solutions) called population, and then solutions from one population are used to generate a new population by three operators (Figure 2): reproduction, crossover and mutation. 
Reproduction consists in selecting chromosomes from the population, the best should survive and create new offspring. Crossover selects genes from parent chromosomes and creates new offspring. Afterwards, mutation takes place, changing randomly the new offspring, in order to prevent all solutions in the population falling into the local optimum of solved problems.

\subsection{Simulation procedure}

The simulation procedure has a bi-level structure (Figure 3): the first level is represented by a system of static sticastic traffic assignment models that allow to estimate the origin-destination path choice probabilities on the first k-paths of

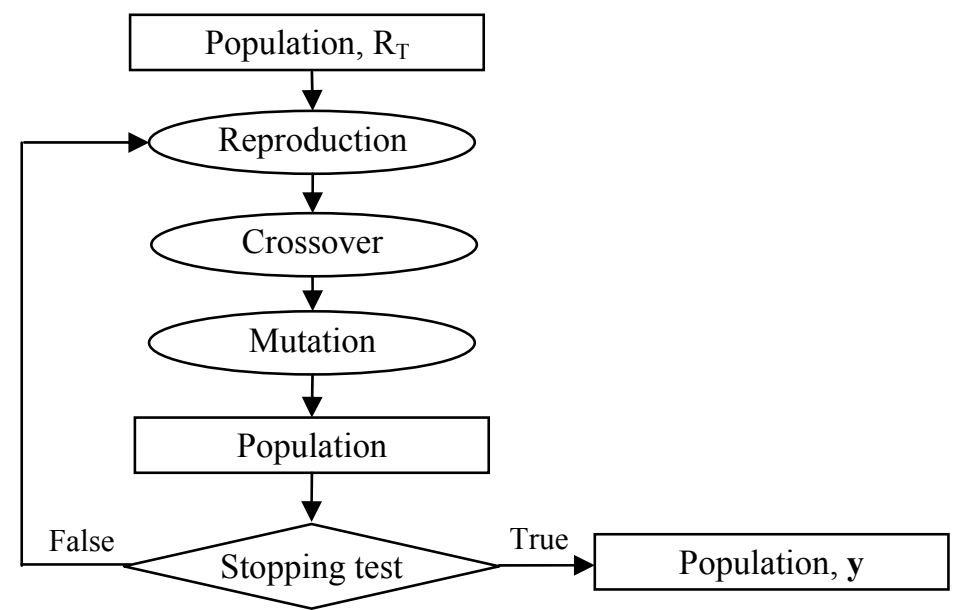

Figure 2: Structure of the genetic algorithm.

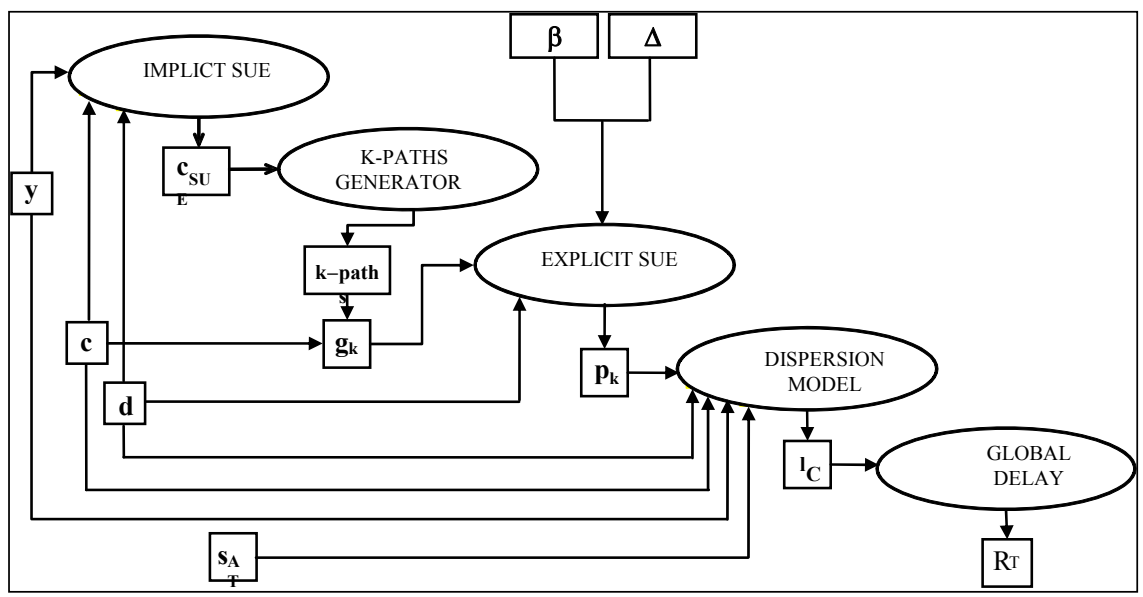

Figure 3: $\quad$ Structure of the simulation procedure. 
minimum congested costs on every origin-destination couple; the second level is represented by a system of dynamic models that allow to estimate the temporal profile of in-flows and out-flows to and from different accesses and, therefore, to estimate the total delay on the network.

The system of static simulation models is represented by:

- a Stocastic User Equilibrium, SUE, model with implicit path enumeration, that provides an estimation of congested link costs vector, c $_{\text {SUE }}$;

- a k-paths generator, that provides the first k-paths of minimum congested costs on every origin-destination couple;

- a Stocastic User Equilibrium, SUE, model with explicit enumeration of the first k-paths of minimum congested costs, which provides an estimation of path choice probability vector, $\mathbf{p}_{\mathbf{k}}$, according to the equilibrium constraint.

The system of dynamic simulation models is represented by:

- a dispersion model (aggregate link cost functions) that allows to estimate the temporal profile of in-flows and out-flows to and from different accesses and, therefore, the vector of queue lenghts on links, $\mathbf{l}_{\mathbf{C}}$;

- a model for the estimation of the global delay on the network, $\mathrm{R}_{\mathrm{T}}$.

\section{Conclusion}

The paper proposes a system of models and procedures for signal setting design of signalized intersections in a road network with endogenous estimation of origin-destination path flows. It is able to support the design of a signalized road transport network both in ordinary and evacuation conditions. The aim is to provide both methodological and practical guidelines for signal setting design of signalized intersections in a road network.

\section{References}

[1] Russo F. \& Vitetta A., Risk evaluation in a transportation system. International Journal of Sustainable Development and Planning, 1 (2), pp. 170-191, 2006.

[2] Cantarella G.E. \& Vitetta, A., The multi-criteria road network design problem in an urban area. Transportation, 33 (6), pp. 567-588, 2006.

[3] Russo F, Vitetta A., An assignment model with modified Logit, which obviates enumeration and overlapping problems. Transportation, 30 (3), pp. 177-201, 2003.

[4] Russo F. \& Vitetta A., A topological method to choose optimal solutions after solving the multi-criteria urban road network design problem. Transportation, 33 (4), pp. 347-370, 2006.

[5] Cantarella G.E. Pavone, G. \& Vitetta A., Heuristics for urban road network design: Lane layout and signal settings. European Journal of Operational Research, 175 (3), pp. 1682-1695, 2006. 
[6] Russo F. \& Vitetta A., Safety of users in road evacuation: General methodology and main results. Proc. of Urban Transport XIII, Urban Transport and the Environment in the 21st century, Brebbia C. A. (ed.), WIT Press, Southampton, pp. 763-772, 2007.

[7] Russo F. \& Rindone C., Safety of users in road evacuation: planning internal processes and guidelines. Proc. of Urban Transport XIII, Urban Transport and the Environment in the 21st century, Brebbia C. A. (ed.), WIT Press, Southampton, pp. 825-834, 2007.

[8] Russo F. \& Rindone C., Safety of users in road evacuation: the logical framework approach in evacuation planning. Proc. of Urban Transport $X I V$, Urban Transport and the Environment in the 21st century, Brebbia C. A. (ed.), WIT Press, Southampton, pp. 751-760, 2008.

[9] Russo F. \& Rindone C., Safety of users in road evacuation: Modelling and DSS for LFA in the planning process. Proc. of Sustainable Development and Planning $I V$, vol.1, Brebbia C. A. (ed.), WIT Press, Southampton, pp. 453-464, 2009.

[10] Russo F. \& Chilà G., Safety of users in road evacuation: demand models. Proc. of Urban Transport XIII, Urban Transport and the Environment in the 21st century, Brebbia C. A. (ed.), WIT Press, Southampton, pp. 773$782,2007$.

[11] Russo F. \& Chilà G., Safety of users in road evacuation: RP vs. SP surveys in demand analysis. Proc. of Urban Transport XIV, Urban Transport and the Environment in the 21st century, Brebbia C. A. (ed.), WIT Press, Southampton, pp. 703-713, 2008.

[12] Russo F. \& Chilà G., Safety of users in road evacuation: Modelling and DSS for demand. Proc. of Sustainable Development and Planning IV, vol.1, Brebbia C. A. (ed.), WIT Press, Southampton, pp. 465-474, 2009.

[13] Vitetta A., Musolino G. \& Marcianò F.A., Safety of users in road evacuation: Supply and demand-supply interaction models for users. Proc. of Urban Transport XIII, Urban Transport and the Environment in the 21st century, Brebbia C. A. (ed.), WIT Press, Southampton, 2007.

[14] Vitetta A., Musolino G. \& Marcianò F. A., Safety of users in road evacuation: calibration of cost functions and simulation. Proc. of Urban Transport XIV, Urban Transport and the Environment in the 21st century, Brebbia C. A. (ed.), WIT Press, Southampton, pp. 715-725, 2008.

[15] Vitetta A., Musolino G. \& Marcianò F.A., Safety of users in road evacuation: Modelling and DSS for transport supply and supply-demand interaction. Proc. of Sustainable Development and Planning IV, vol.1, Brebbia C. A. (ed.), WIT Press, Southampton, pp. 475-484, 2009.

[16] Vitetta A., Quattrone A. \& Polimeni A., Safety of users in road evacuation: design of path choice models for emergency vehicles. Proc. of Urban Transport XIII, Urban Transport and the Environment in the 21st century, Brebbia C. A. (ed.), WIT Press, Southampton, pp. 803-812, 2007.

[17] Vitetta A., Quattrone A. \& Polimeni A., Safety of users in road evacuation: algorithms for path design of emergency vehicles, Proc. of Urban 
Transport XIV, Urban Transport and the Environment in the 21st century, Brebbia C. A. (ed.), WIT Press, Southampton, pp. 727-737, 2008.

[18] Vitetta A., Quattrone A. \& Polimeni A., Safety of users in road evacuation: Modelling and DSS for paths design of emergency vehicles. Proc. of Sustainable Development and Planning IV, vol.1, Brebbia C. A. (ed.), WIT Press, Southampton, pp. 485-495, 2009.

[19] Di Gangi M. \& Velonà P., Safety of users in road evacuation: pedestrian out flow models in a building. Proc. of Urban Transport XIII, Urban Transport and the Environment in the 21st century, Brebbia C. A. (ed.), WIT Press, Southampton, pp. 803-812, 2007.

[20] Di Gangi M., Velonà P. \& Catanzariti A., Safety of users in road evacuation: some enhancement in modelling pedestrian evacuation of a building, Proc. of Urban Transport XIV, Urban Transport and the Environment in the 21 st century, Brebbia C. A. (ed.), WIT Press, Southampton, pp. 739-749, 2008.

[21] Di Gangi M., Safety of users in road evacuation: modelling and DSS for pedestrian outflow. Proc. of Sustainable Development and Planning IV, vol.1, Brebbia C. A. (ed.), WIT Press, Southampton, 2009.

[22] Cantarella G. E. \& Vitetta A., La regolazione di intersezioni stradali semaforizzate: metodi ed applicazioni, FrancoAngeli, Milan, 2010.

[23] Allsop R.E., SIGSET: A computer program for calculating traffic capacity of signal-controlled road junctions. Traffic Engineering \& Control,12, pp. 58-60, 1971.

[24] Improta G. \& Cantarella G.E., Control systems design for an individual signalised junction. Transportation Research 18B, pp. 147-167, 1984.

[25] Cantarella G.E. \& Improta G., Capacity Factor and Cycle Time Optimization for Signalized Junctions: A Graph Theory Approach. Transportation Research 22B, pp. 1-23, 1988.

[26] Webster F.V., Traffic Signal Setting, Road Research Laboratory Technical Paper 39, London, UK, 1958.

[27] Webster F.W. \& Cobbe B.M., Traffic Signals, Road Research Technical Paper 56, Road Research Laboratory, HMSO, London, 1966.

[28] Allsop R.E., SIGCAP: A computer program for assessing the traffic capacity of signal-controlled road junctions. Traffic Engineering \& Control,17, pp. 338-341, 1976.

[29] Akcelik R. \& Besley M., SIDRA user guide, Part 2, Input, ARRB Transport Research Ltd., Report No. WDTE91/012B, Victoria, Australia, 143p., 1992.

[30] Burrow I.J., OSCADY: a computer program to model capacities, queues and delays at isolated tra.c signal junctions, TRRL Report, 105, Transport and Road Research Laboratory, Crowthorne, 1987.

[31] Little J.D.C., The synchronisation of traffic signals by mixed-integer-linearprogramming. Operations Research, 14, pp. 568-594, 1966.

[32] Little J.D.C., Kelson M.D. \& Gartner N.H., MAXBAND: A program for setting signals on arteries and triangular networks. Transportation Research Record, 795, pp. 40-46, 1981. 
[33] Robertson D.I., 'TRANSYT' method for area traffic control. Traffic Engineering and Control, 10, pp. 276-81, 1969.

[34] Marcianò F.A., Una metodologia per il progetto dei parametri di regolazione di una rete di intersezioni stradali semaforizzate: sperimentazione in condizioni di emergenza, $\mathrm{PhD}$ thesis, Mediterranea University of Reggio Calabria, 2010. 